\title{
Evaluation of an Intervention Program to Foster Self-Regulated Learning and Academic Achievement in Latin Instruction
}

\author{
Daniela Wagner and Franziska Perels \\ Department of Educational Research, Saarland University, Building A4 2, Room 4.19, 66123 Saarbrücken, Germany \\ Correspondence should be addressed to Daniela Wagner, daniela.wagner@mx.uni-saarland.de
}

Received 20 September 2012; Accepted 10 October 2012

Academic Editors: R. Martens and G. Sideridis

Copyright (C) 2012 D. Wagner and F. Perels. This is an open access article distributed under the Creative Commons Attribution License, which permits unrestricted use, distribution, and reproduction in any medium, provided the original work is properly cited.

\begin{abstract}
The study's aim was to develop two different intervention programs and to evaluate their contribution to students' self-regulated learning and academic achievement in Latin classes. The concept of our study referred to a process-focused model of self-regulated learning that divides the phases of the self-regulated learning process into different areas, which we applied to domain-specific translation strategies. Within a pre-, post-, and follow-up-test design with 109 tenth graders, self-regulated learning skills and translation competency as well as translation strategy application were assessed using both a self-regulation questionnaire and a standardized translation test. Three different conditions were compared: (a) combined training group (ComG): self-regulated learning and translation, (b) translation training only (TG), and (c) control group (CG). The intervention consisted of nine sessions spread over a period of three weeks. Results of analyses of variance with time as a repeated measurement indicated interaction effects between time and groups for self-regulated learning in favor of the intervention groups. The ComG showed marginally higher self-regulatory skills than the TG. Regarding the translation competencies as well as the strategy application, the results revealed significant training effects in comparison to the control group, with the TG showing the highest increase.
\end{abstract}

\section{Introduction}

Today's fast-changing demands of the environment increasingly promote the necessity of self-regulatory competencies and the awareness of the importance of lifelong learning skills [1]. That is why it is essential to prepare young people for the challenge of both professional and private life beyond school beginning as early as their formative school years or even in kindergarten $[2,3]$. In order to contribute to the promotion of self-regulated learning strategies in school, we implemented an intervention program within regular class. The aim was to investigate the regulation of the translation process in Latin instruction and thus to shed light on studies on self-regulated learning in a new domain-specific field. Since the teaching style in Latin is often said to be classical and old-school rather than innovative and autonomy-supportive, our study wants to focus on the gains that self-regulated learning supplies. Specifically, our study contributes to strategic approaches to texts in Latin and intends to prove that self-regulated learning is of particular importance for translation competency as well as translation strategy application. Translation competency concerns the final product of the translation process, that is, the quality of the text in the target language; the application of translation strategies is considered to be the tool that helps to transmit the meaning of the original text into the target language. The main goal of Latin instruction is to prepare learners for the comprehension and interpretation of original texts in Latin. That is why translation work, respectively, the precise recoding of Latin texts into the target language, is the most important part in Latin instruction. In general, translation work in Latin class is regarded as one of the most challenging forms of language work [4]. It is argued that translating skills are comparable with problem-solving skills [5], for the reason that problems arise during the translation process so that the right strategies have to be found to solve them. Consequently, Latin students have to be equipped with self-regulatory strategies that support their translating. Additionally, even though it is controversial that learning Latin has transfer effects on the acquisition of other foreign languages [6], 
research could show that translation skills in Latin contribute to reading literacy $[7,8]$ and verbal competence (e.g., comprehending complex connections, drawing conclusions, reflecting precise understanding) [9]. Since the relevance of the texts' contents in Latin may not be very evident for young people sometimes, Latin instruction has to adapt to the learning habits of today's young people and has to refocus the teaching of Latin as a language. In addition to innovative teaching methods [10] and the demand for reflection and comprehension skills, active and independent learning plays an important role of competency-based education. It is vital to convey the message that the ability to deal with complex Latin texts can be considered as a path to important proficiencies that go beyond the practicing of vocabulary and grammar, but also include analytical skills that are essential for lifelong learning [9].

The major aim of the present study was to evaluate the effectiveness of different kinds of training interventions. Specifically, we wanted to demonstrate that students benefit more from a combined training of self-regulatory and Latin translation strategies than from a segregated impartment of these strategies.

The concept of our trainings referred to the theoretical framework of Pintrich [11], who defined self-regulated learning as "an active, constructive process whereby learners set goals for their learning and then attempt to monitor, regulate, and control their cognition, motivation, and behavior, guided and constrained by their goals and the contextual features in the environment" [11, page 453]. Pintrich's model emphasizes the procedural character of self-regulated learning by classifying the learning process into four phases of regulation (forethought, planning, and activation; monitoring; control; reaction and reflection). These regulatory activities are further subdivided in four regulation areas (motivation, cognition, behavior, and context), which for their part consist of components representing favorable strategies of selfregulated learning (e.g., time planning, resource management strategies). Since there is evidence that the impartment of cross-curricular strategies should always be combined with the teaching of domain-specific strategies [12], we adopted the Latin translation process in conjunction with the self-regulated learning process by subdividing the translation process into three different phases (analysis/decoding, transfer/recoding, and restructuring) [13].

Concerning the contents of our training programs, we were generally oriented toward theoretical assumptions of self-regulated learning and didactical knowledge of translation work in Latin instruction $[10,14]$. We assumed in our model (cf. Figure 1) that both theoretical considerations are interrelated and form together a powerful framework to optimize effects on self-regulated learning, translation competency as well as on the application of translation strategies.

Since there is little empirical evidence for a definite separation of monitoring and control processes [11], we considered both phases together in the model. Because of that arrangement, our model is similar to the cyclical model of self-regulated learning by Zimmerman [16], which depicted the learning process in three phases: forethought, performance, and self-reflection.
In the following section, we present the important strategies of the different phases of the self-regulation and translation process.

The process of self-regulated learning starts with the planning phase, during which the setting of goals with regard to a task plays a decisive role. Activities that are important in this phase include the activation of prior knowledge [11] and raising awareness of motivationally advantageous goal orientations [17] that are characterized by high self-efficacy beliefs [18]. Interest with regard to the task is also influential on the motivational orientation [19]. For the purpose of this study, the operationalization of interest involved the preference of Latin as a subject, and for activities that are related to Latin (e.g., translating Latin texts), and was regarded as a determinant that contributes to intrinsic motivation $[20,21]$.

In addition, we laid great stress on self-motivation strategies, such as promising oneself extrinsic rewards (e.g., watching a favorite TV series, meeting friends), as they help to sustain students' motivation toward the task [22].

Planning one's behavior also belongs to essential aspects of the learning process. In this context, strategies for learners may involve time-management activities (e.g., setting up time schedules or reserving fixed time frames for homework) $[11,23,24]$.

Moreover, the study environment (e.g., classroom, situation at home) requires specific self-regulatory strategies. In order to obtain a first overview of the situation before starting the actual learning process, the learners have to perceive the demands of the context (e.g., possible distractions). The application of translation strategies helps to sustain the awareness of translation as a process and presents the opportunity to reflect on the structure and content of the text. In the special case of translation work in Latin instruction, some essential translation strategies for each phase were integrated into our program. We were oriented toward the model of translation by Nida and Taber [13] that made a distinction between three phases of translating a text.

In the phase of analysis/decoding, we further differentiated between the selection of elaborational and organizational strategies which should be used in order to prepare the text for the actual translation.

Elaborational strategies refer to activities such as thinking about the headline or making use of introductory words, making notes while reading a text or creating mental images [25]. With regard to translation work, the consideration of the semantic functions is particularly important as semantics covers the students' meaning and interpretation of words and sentences. By asking oneself questions and formulating content-related expectations $[10,14]$, the learner develops a first understanding of the basic messages of the text.

Organizational strategies, however, are targeted toward outlining and structuring of a text [25] and help to organize the information in the first reading. Furthermore, these strategies include clarifying of unknown vocabulary and analyzing the grammatical elements and syntactic functions by following the grammatical-syntactical approach $[10,13]$. The central idea of that approach is the analysis and the underlining of constituents that sentences are composed of, and of the specific grammatical function they serve. 


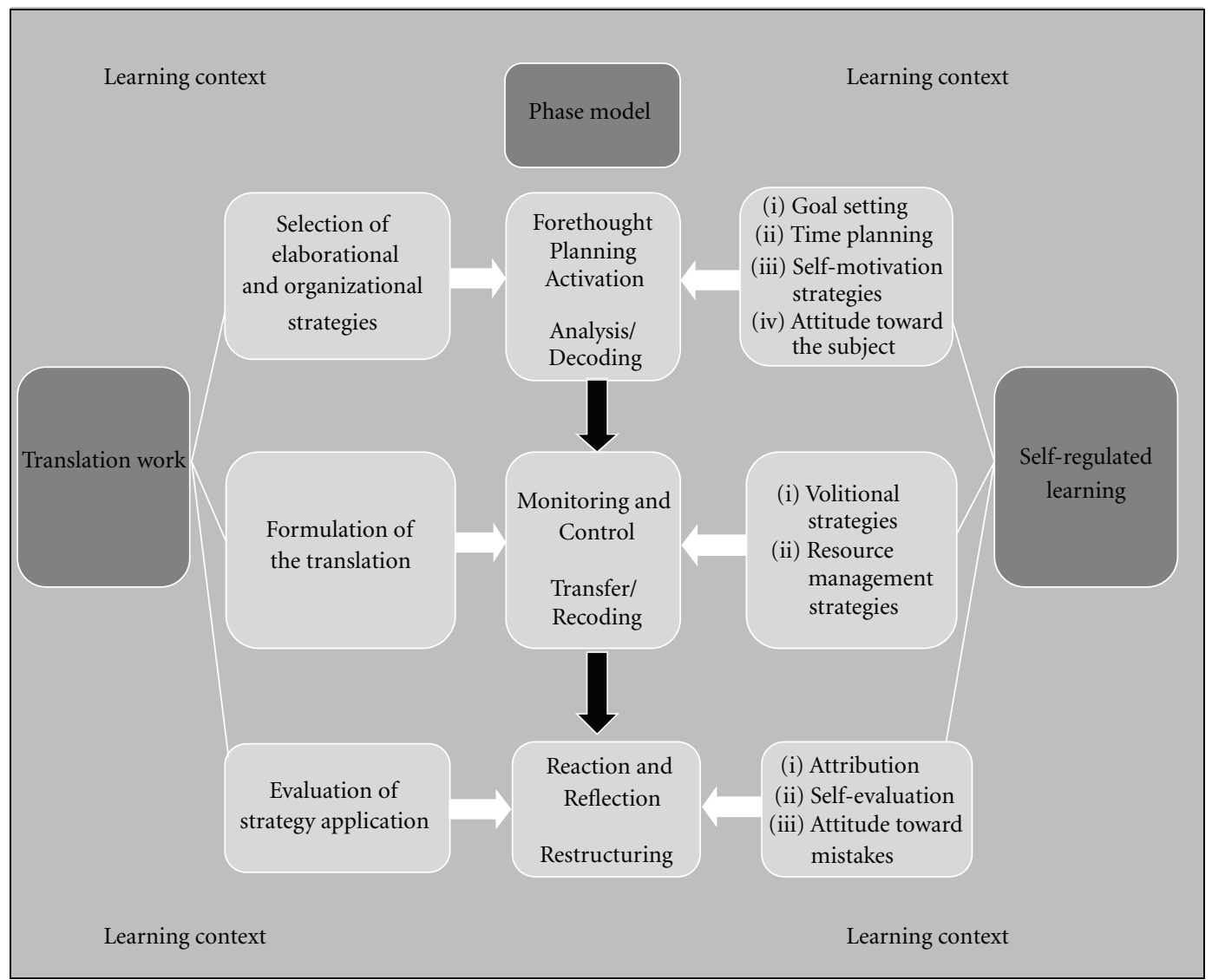

Figure 1: Model of self-regulated translation (adapted from [15]).

During the monitoring and control phase, the selection and adaptation of strategies for managing volitional factors are important. In our trainings, we emphasized the employment of volitional control strategies [26], as they help learners to stay focused on the task and their goals even if negative emotions (e.g., anxiety or disappointment) or distractions in the environment threaten to impact learning negatively [27], or favor procrastinating the performance of a task [28]. Besides, resource management strategies can be applied when confronted with changing conditions or encountering unforeseen problems. Learners have to observe and flexibly regulate their effort and time, and they have to study the environment when something does not unfold as planned.

In the phase of transfer/recoding the learners document their understanding of the text by transposing the text's content into the target language. Since Latin sentences are mostly of high complexity and structurally unusual, it is challenging for people today to transfer the meaning of the original text into the target language successfully and to formulate a logical and understandable translation. That is why it is very important to have a well-decoded text as foundation for the transfer and recoding.

After task completion, in the phase of reflection and reaction, learners try to understand the reasons for success or failure and reflect the outcome of their performance by attributing it to either ability, luck, or effort. Accordingly, attributing success to internally stable factors, such as one's abilities, and failure to an external, uncontrollable factor, such as luck, is most beneficial for self-esteem and motivation [29].

In this context, it is important to adopt a positive attitude toward making mistakes in such a way that accepting mistakes becomes part of the learning process and is viewed as an opportunity to learn [30]. Eventually, the comparison of the final goal attainment with the original goals and the self-evaluation of personal progress might lead to new beliefs that influence future goal settings and task processing.

After having completed the translation, the learners have to evaluate their strategy application by reviewing the wording, by correcting, and if necessary restructuring the word order to conform to norms of the target language.

The general aim of our training programs was to take the overall process of self-regulated translating into consideration by enhancing several components of each phase of self-regulated learning and translation work. Choosing this approach, we expected to be able to analyze students' selfregulated behavior in a more differentiated manner.

1.1. Assessing Self-Regulated Learning. As far as the measurement of self-regulated learning is concerned, previous studies have demonstrated that it can be assessed either as 
an aptitude, referring to a person's stable attributes that predict prospective behavior, or as an event that allows more complex and procedural analyses along a timeline [31, 32]. There are questionnaires which are approved and often used, such as the Learning and Study Strategies Inventory (LASSI) [33], the Motivated Strategies for Learning Questionnaire (MSLQ) [31], and the Inventory for Recording Learning Strategies in Academic Studies (LIST) [34], which is based on the previously named instruments. This way of measuring is confined to self-report data that, on the one hand, leads to a generalization of actions rather than to a description of the immediate experience of the situation and, on the other hand, is easy to be gathered and scored [32]. Regarding the measurement of self-regulated learning as a process, methods such as think-aloud techniques, direct observations, and standardized learning diaries were developed in order to assess self-regulatory strategies more continuously with regard to enhancing self-regulatory and reflective behavior. In our study, we focused on a questionnaire as a method to assess self-regulated learning, employing frequently used items to provide data on how students plan, monitor, control, and reflect their cognition, motivation, and behavior in their learning environment [35]. The questionnaire was supplemented by a standardized translation test that collected data on students' translation competency as well as on their application of translation strategies.

1.2. Fostering Self-Regulated Learning. Earlier studies on intervention programs for fostering self-regulated learning have reported how training results in the enhancement of self-regulatory abilities and academic achievement [36, 37]. Perels et al. [38] demonstrated the effectiveness of selfregulation training in regular math classes. In addition, the findings of a large body of research studies have revealed that trainings which combine the teaching of self-regulatory strategies with domain-specific strategies are more efficient than trainings that focus on strategies in isolation $[12,39]$. Most of these studies operate in the fields of mathematics [38-40], reading [41, 42], writing [43] or web-based learning environment [44]. Studies on self-regulation in foreign language learning, however, are underutilized and are mostly restricted to English as a foreign language (EFL) [45] or cover special fields such as vocabulary acquisition [46] or language learning strategy use [47].

Generally, we found no studies discussing the effects of self-regulated learning and translation work in foreign language teaching. Moreover, there has not been any research on the simultaneous promotion of self-regulated learning and translation competency in Latin instruction, which was the aim of the present study. For this purpose, we designed two training programs which consisted of components of self-regulated learning and Latin translation. Specifically, our research interest focused on examining the effectiveness of these programs on enhancing students' self-regulatory abilities as well as on their translation competency and translation strategy application and to analyze changes that occurred between a pre- and a posttest. Additionally, we wanted to test whether a combined training of self-regulatory and translation components would lead to better results than just teaching one of these components. Our major hypothesis of the study was that each of the programs would have a positive impact on students' self-regulated learning, translation competency, and strategy application and that the training groups would outperform a control group that was not involved in the training. We specifically expected that the combination group (ComG) would outperform the pure translation group (TG) in the questionnaire concerning selfregulatory competencies as well as in the translation test concerning both the overall translation competence and the strategy application. In case that the implementation of the programs led to improved learning skills, students would be provided with the opportunity to practice and internalize the acquired competencies. Our assumption was that the data of the variables would not change significantly between the posttest and a stability measurement (follow-up test), so that no additional effect eight weeks after the intervention would occur. Nevertheless, it was expected that the participants of the intervention would have higher levels in terms of the dependent measures and that the ComG would still show the highest gains.

\section{Method}

2.1. Participants and Design. The study was conducted in six German grammar schools. Participation was voluntary and parental permission was required. The overall study was quasiexperimental and a pretest-posttest control group design was used in order to analyze the effectiveness of the treatment. Long-term effects were examined with a retention test eight weeks after the posttest. In general, we differentiated between three groups: a combined training group (ComG), which was trained in self-regulated learning and Latin translation strategies; a group that was only trained in Latin translation strategies (TG); and a control group without training (CG). A group that received only selfregulated strategy training could not be incorporated into the design due to actualities of the schools' situation.

The combined group consisted of 41 students, the translation group of 32, and the control group of 36 students. Altogether, 109 students of the tenth grade took part in the study. The mean age of participants was $15.72(\mathrm{SD}=0.56)$, and $53.2 \%$ of participants were female.

The different groups were homogenous in terms of age, gender and the mean marks of the last report card in Latin (ComG: 2.53, SD = 0.77; TG: 2.63, SD = 1.07; CG: 2.94, $\mathrm{SD}=0.95)$.

2.2. Procedure. For the pretest, self-regulated learning abilities, the application of Latin translation strategies, and the quality of the Latin translation which was prepared were rated by means of a self-regulation questionnaire and a standardized translation test one week before the intervention. The same questionnaire and a comparable test were utilized one week (posttest) after the intervention. During the period between pre- and posttest ( 3 weeks), the training program 
for the experimental group, that is, training groups, was conducted, which consisted of three 45 minutes sessions in the regular lesson on a weekly basis. After a period of eight weeks, the participants of the training groups got the same questionnaire again as well as another test-comparable to the posttest regarding difficulty and length-in order to measure the stability of the training effects.

The control group underwent only the pre- and posttesting because the drop-out rate of students was too high in the follow-up testing. Between the two points of measurement, the CG did not get any special intervention but was instructed by their regular teacher in learning strategies for dealing with complex texts in Latin. Concerning the learning contents and the time setting, a parallel instruction of both the control and the training groups could be guaranteed to the greatest possible extent. It was important that the control group would deal with texts in prose form rather than with lyric texts, since the training programs entirely concentrated on prose that requires a different approach than poetry.

The training of the intervention groups started shortly after the pretest and was conducted by two specialized trainers, who also took charge of testing.

2.3. Intervention. In order to depict the intervention program, we primarily focus on the combined training program which included both self-regulatory and translation components. Variations of the full training program (ComG) included that the aspects of self-regulated learning were left out in the TG and instead more emphasis was placed on the translation process. According to the school's circumstances, it was not possible that the ComG dealt $45 \mathrm{~min}$ with selfregulated learning and got additional $45 \mathrm{~min}$ for translation work which would have guaranteed absolute parallelism of instruction.

Over the course of nine lessons, the students of the ComG had to work on different exercises, including aspects of their learning in general (15 min) as well as domain-specific tasks that specifically trained them to deal with Latin texts (30 min). The domain-specific tasks were based on the curriculum for the tenth grade. In general, we tried to utilize methods and arrangements of interactive learning in order to promote self-regulated learning.

We integrated general learning strategies that are typical for the particular phases of self-regulated learning (e.g., goal setting, time planning, self-motivation strategies, attitude toward a subject, volitional strategies, resource management strategies, attribution, attitude toward mistakes, and selfevaluation) and domain-specific translation strategies for each phase of the translation process. In the TG, we concentrated on instructing translation strategies (decoding, recoding, restructuring) for dealing with complex Latin texts. The CG did not receive special training, but learned about translation strategies in regular class to maintain a reasonable equality of instruction.

The sessions' arrangement in each week followed the contents of the different phases of self-regulated learning. In the second week, for example, we focused on volitional strategies and on the formulation of the translation (cf. Figure 1).
Table 1 gives a particular overview of the contents.

The instructors always started with a repetition of the preceding lesson and the discussion of the students' homework. Afterwards, one self-regulatory and one domain-specific strategy were covered. The lesson ended with a short review and homework assignments. The first three sessions served to gather students' expectations and to inquire about their attitude toward Latin as a subject. Furthermore, the students were made familiar with self-regulatory strategies that are important in the planning phase of the learning process (realistic goal setting, effective time planning, self-motivation) and with helpful decoding strategies (e.g., questioning, marking, structuring). In order to gain a first impression of the topic the Latin texts were dealing with, the students reciprocally read the first text in pairs, and, after each passage, they explained to their partner what they had understood so far and how the text probably will continue. By this, previous knowledge was activated and a first understanding was established.

In the next sessions that were oriented toward the monitoring/control and the transfer/recoding phase, students started translating the text by benefitting from their previous decoding. In terms of self-regulated learning, strategies such as prohibiting procrastination and techniques including dealing with distractions (both internal and external), rewording disturbing thoughts, concentration, and relaxation were introduced. In addition, students were always encouraged to discuss their personal experiences and to consult each other. The last week sessions covered strategies such as handling mistakes or possibilities of favorable causal attribution. Regarding the domain-specific contents, the students evaluated their strategy application and examined their translated text in terms of correctness and logic in the target language. In case of logical flaws, they learned how to restructure and reword the text. Moreover, they analyzed typical mistakes they make when translating and deepened the application of translation strategies by putting jigsaw pieces of a text in the correct order. By this, they were supposed to get an additional understanding of logic and structure of Latin texts. In the last session, we compared the students' initial expectations and goals with their final impression of the training.

\subsection{Instruments}

Self-Regulation Questionnaire. A standardized self-regulation questionnaire was used to measure the students' selfregulated learning. The responses were rated on a scale with scores ranging from 1 to 4 (1: definitely not true; 2: tends not to be true; 3: tends to be true; 4: definitely true). Altogether, the questionnaire consisted of 71 items that were summed up to create four scales (planning, monitoring/control, and reflection) representing the different phases of the framework for self-regulated learning by Pintrich [11]. In this study, these scales were aggregated into an overall scale self-regulated learning.

The analyses of the internal consistencies (Cronbach's $\alpha$ ) of all scales yielded satisfactory results (cf. Table 2) both in 
TABLE 1: Topics of the intervention program.

\begin{tabular}{|c|c|c|}
\hline \multirow[b]{2}{*}{ Session } & \multicolumn{2}{|c|}{ Learning contents of the training groups exemplarily for the ComG } \\
\hline & Self-regulative content & Translation content \\
\hline $\begin{array}{l}\text { 1st and 2nd } \\
\text { sessions }\end{array}$ & $\begin{array}{l}\text { Introduction of self-regulative strategies } \\
\text { Expectations } \\
\text { Attitude toward Latin }\end{array}$ & \\
\hline 3rd session & $\begin{array}{l}\text { Goal setting } \\
\text { Time planning }\end{array}$ & $\begin{array}{l}\text { Introduction to the topic } \\
\text { Organizational and elaborational strategies }\end{array}$ \\
\hline 4th session & Self-motivation & Organizational and elaborational strategies \\
\hline 5th session & $\begin{array}{l}\text { Procrastination } \\
\text { Dealing with internal and external distractions }\end{array}$ & $\begin{array}{l}\text { Formulation of the translation } \\
\text { Formulation of the translation }\end{array}$ \\
\hline $\begin{array}{l}\text { 6th and 7th } \\
\text { sessions }\end{array}$ & $\begin{array}{l}\text { Concentration } \\
\text { Relaxation } \\
\text { Raising the awareness of how to translate strategically }\end{array}$ & $\begin{array}{l}\text { Formulation of the translation } \\
\text { Formulation of the translation }\end{array}$ \\
\hline 8th session & $\begin{array}{l}\text { Handling mistakes } \\
\text { Attribution }\end{array}$ & $\begin{array}{l}\text { Evaluation of strategy application, restructuring } \\
\text { Text jigsaw puzzle }\end{array}$ \\
\hline 9th session & Comparison of initial goal with final impression & Typical mistakes \\
\hline
\end{tabular}

TABLE 2: Summary of reliability estimates.

\begin{tabular}{lccccc}
\hline Scales & Items & \multicolumn{3}{c}{ Reliability (Cronbach's $\alpha)$} & Example \\
\hline OVERALL/scales self-regulated learning & $\mathbf{7 1}$ & $\mathbf{t}_{\mathbf{1}} . \mathbf{8 7}$ & $\mathbf{t}_{\mathbf{2}} . \mathbf{8 8}$ & $\mathbf{t}_{3} . \mathbf{8 8}$ & \\
$\quad$ & 25 & $t_{1} .85$ & $t_{2} .89$ & $t_{3} .86$ & I make good use of my study time in Latin instruction. \\
Planning & 30 & $t_{1} .92$ & $t_{2} .94$ & $t_{3} .93$ & When I study, I find my mind wandering to other things. \\
Monitoring and control & 16 & $t_{1} .79$ & $t_{2} .85$ & $t_{3} .84$ & After studying, I think about what to improve. \\
$\quad$ Reflection & & &
\end{tabular}

Note. $t_{1}$ : pretest; $t_{2}$ : posttest; $t_{3}$ : follow-up-test.

the pre- and the post- and follow-up-test. The validity of the questionnaire was ascertained by using items from established instruments $[12,31,48]$, whereas some items were newly developed, if necessary. The standardized completion of the questionnaire was guaranteed by investigators that gave the necessary instructions during regular classes.

Translation Test. In order to measure the translation competency and the application of translation strategies, students were provided with an experimenter-designed translation test which was criterion referenced. The translation competencies were measured by the quality of the final translation that was prepared. The assessment of the application of translation strategies referred to initial preparations of the text as well as to the final evaluation of strategy use. At each point of measurement different texts were used that all had a parallel structure as well as the same amount of difficulties (e.g., grammatical constructions). The texts were kept in prose form and were oriented toward Cicero's rhetorical

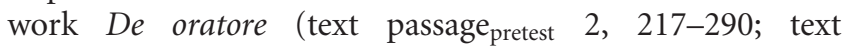
passage posttest $_{2}$, 18, 75; text passage follow-up-test $_{\text {which was not }}$ based on an original text, but was completely self-formulated). The texts were invariably designed in conjunction with experts in order to ensure content validity. The degree of difficulty of the texts was quite high $\left(P_{t 1}=.15 ; P_{t 2}=\right.$ $\left..22 ; P_{t 3}=.14\right)$, which was necessary since the students had to be challenged to decode the text strategically rather than merely translate it word for word. The text was subdivided in four parts, in which the students could reach a maximum number of 15 points for the overall translation competency and 9 points for the application of translation strategies. For the analysis of both the quality of the translation (translation competency) and the application of strategies, raters used a schema and were blind to each other's scores. Interraterreliability was within adequate limits (Cohen's $\kappa$ was 0.81 for the pretest, 0.83 for the posttest, and 0.85 for the follow-uptest).

\section{Results}

The primary purpose of our study was to investigate the effectiveness of different intervention programs with regard to the enhancement of self-regulatory abilities as well as of translation competency and translation strategy application. The hypotheses postulated that training leads to an improvement of self-regulated learning as well as of achievement variables whereas the control group is stable. Specifically, we assumed that the self-regulated learning abilities as well as the translation competence and the translation strategy application of the ComG would increase the most.

The dependent measures were analyzed using a 3 (pretest/posttest/follow-up-test) $\times 3$ (training conditions) analysis of variance with time as repeated measurement factor. Since randomization to the different conditions was not possible, the pretest differences were controlled first. In case of pretest differences, analyses of covariance were conducted to control these differences. 
In terms of pairwise comparisons of the contrasts between the two intervention groups and the control group as well as between the combined group and the translationonly group, the difference between the values before and after the intervention was taken into consideration. For all analyses we selected a 0.05 level of significance.

Table 3 presents the mean scores and standard deviations of the dependent measures (DV) as well as the results of interaction time $\times$ training.

The results of an analysis of variance with time as repeated measurement demonstrated a significant interaction between time $x$ training for the overall scale self-regulated learning (cf. Table 3).

Figure 2 additionally illustrates the results of the overall scale self-regulated learning. The participants of the ComG could improve their self-regulatory competencies, whereas both the TG and CG decreased slightly.

Contrast analyses were conducted for the overall scale self-regulated learning. The hypotheses postulated that the ComG and the TG experienced improved self-regulatory abilities compared to the control group (contrast 1). Moreover, it was expected that the ComG increased the most compared to the TG (contrast 2). Table 4 depicts the contrast coefficients for the analyses.

The analysis of the overall scale self-regulated learning revealed a significant first contrast. This result shows that the training groups (ComG and TG) showed significant higher self-regulatory abilities compared to the control group (cf. Table 5), with the ComG generally showing an improvement and the TG a decline of self-regulatory abilities.

In terms of the second contrast, we obtained a significant result at the $10 \%$ level which indicated only a marginal effect. Thus, the students of the ComG slightly improved their selfregulatory competencies in comparison to the TG.

Concerning the overall achievement variable (translation competency, sum over all demands of the test, max. score: $15)$, we found significant pretest differences between the groups, $F(2,105)=6.58, P=.00$. Therefore, an analysis of covariance (ANCOVA) had to be conducted. After adjusting for pretest scores, our result for the posttest scores indicated a significant training effect for the translation competency (cf. Table 5).

Figure 3 depicts the results of the subscale translation competency. It shows an increase among the participants of ComG and TG but a decline in the CG.

For the translation competency, we also conducted contrast analyses with the difference between the pretest and the posttest. The analyses revealed that both the first and second contrasts were significant (cf. Table 5). Consequently, on the one hand ComG and TG increased their translation competency significantly compared to the control group (contrast 1) and on the other hand the TG showed a higher improvement with regard to the translation competency in comparison to the ComG.

Taking the actual application of translation strategies into consideration, we found significant pretest differences between the groups, $F(2,106)=9.59, P<.001$.

Therefore, results were conducted with an analysis of covariance (ANCOVA) with pretest scores as covariate. As

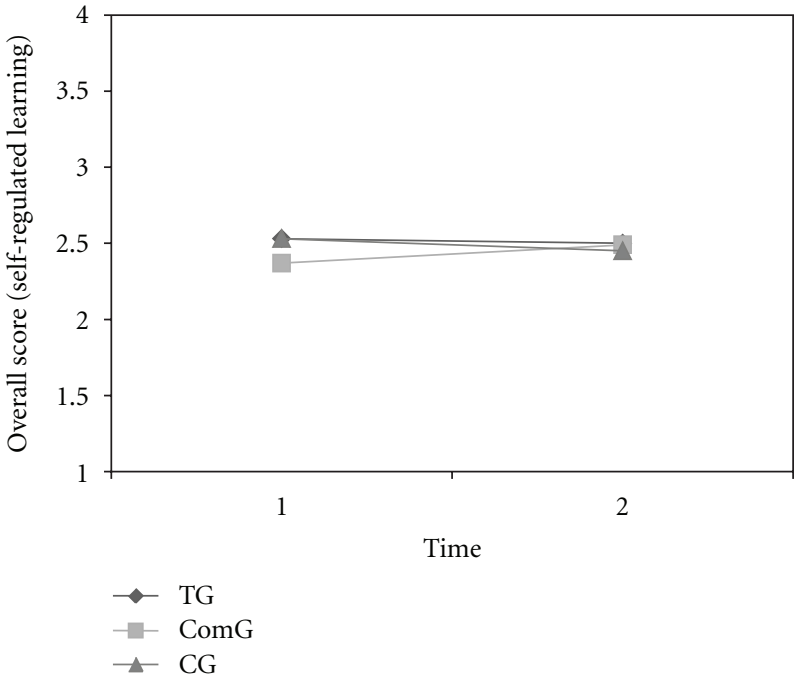

FIGURE 2: Results of the overall scale self-regulated learning.

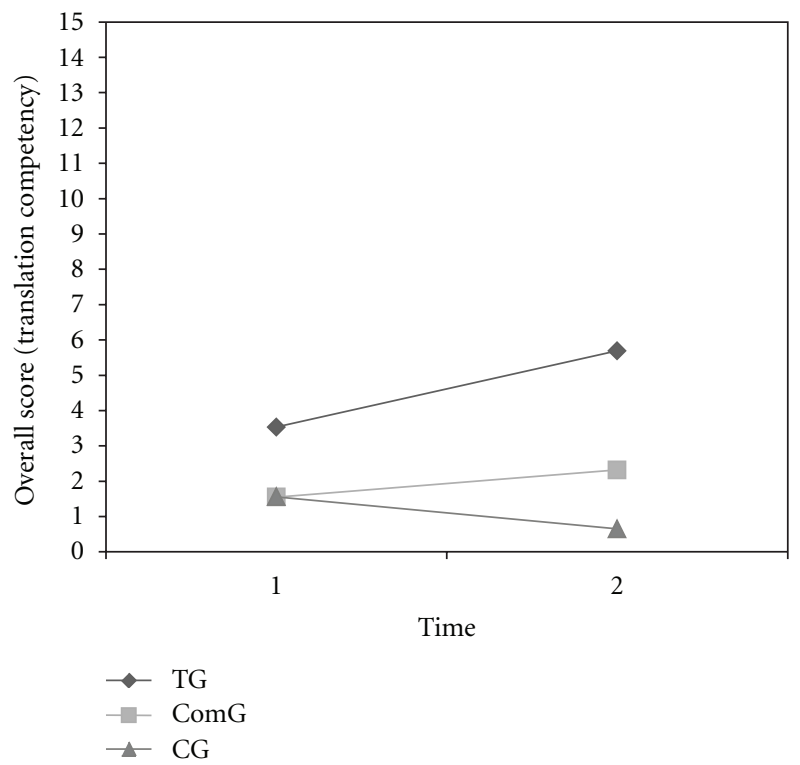

FIgURE 3: Results of the translation competency.

can be seen in Table 3, the ANCOVA displayed a significant training effect for students' strategy application.

Figure 4 shows the results of the application of translation strategies. There was an increase in both the ComG and TG. In contrast, there was a decline in the CG.

The running of contrast analyses revealed two significant contrasts: both intervention groups increased their translation strategy application compared with the control group, and the translation-only group showed a larger increase than the combined group.

The same questionnaire and a further translation test were used eight weeks after the intervention in order to measure the stability of training effects. Because of a high drop-out rate, the stability measurement for the control 
TABLE 3: Mean values (standard deviations) and results of the analysis of variance with time as a repeated measurement.

\begin{tabular}{|c|c|c|c|c|c|c|}
\hline Questionnaire & Group & $\begin{array}{l}\text { Pretest } \\
M(\mathrm{SD})\end{array}$ & $\begin{array}{l}\text { Posttest } \\
M \text { (SD) }\end{array}$ & df & $F$ & $\eta^{2}$ \\
\hline \multicolumn{7}{|l|}{$\overline{D V}$} \\
\hline \multirow{3}{*}{ Overall self-regulated learning (range 1-4) } & TG & $2.53(0.35)$ & $2.50(0.38)$ & \multirow{3}{*}{106} & \multirow{3}{*}{$4.26^{*}$} & \multirow{3}{*}{0.07} \\
\hline & ComG & $2.37(0.43)$ & $2.49(0.45)$ & & & \\
\hline & CG & $2.53(0.42)$ & $2.45(0.49)$ & & & \\
\hline \multicolumn{7}{|l|}{ Translation test } \\
\hline \multirow{3}{*}{ Overall translation competence $^{1}$} & TG & $3.53(3.58)$ & $5.69(3.48)$ & \multirow{3}{*}{105} & \multirow{4}{*}{$33.74^{* * *}$} & \multirow{4}{*}{0.39} \\
\hline & ComG & $1.55(1.94)$ & $2.32(1.84)$ & & & \\
\hline & CG & $1.56(2.08)$ & $0.65(0.99)$ & & & \\
\hline \multirow{3}{*}{ Translation strategy application ${ }^{1}$} & TG & $1.58(2.20)$ & $3.73(2.75)$ & \multirow{3}{*}{105} & & \\
\hline & ComG & $0.63(0.88)$ & $1.59(1.64)$ & & \multirow[t]{2}{*}{$21.77^{* * *}$} & \multirow[t]{2}{*}{0.30} \\
\hline & CG & $0.64(0.75)$ & $0.40(0.72)$ & & & \\
\hline
\end{tabular}

Note. Depended variable, ${ }^{\#} P<.10 ;{ }^{*} P<.05 ;{ }^{* *} P<.01 ;{ }^{* *} P<.001$; TG: translation training only group $(N=32)$, ComG: combined group $(N=41)$, CG: control group $(N=36)$.

${ }^{1}$ Because of pretest differences ANCOVA with pretest values as covariate was conducted.

TABLE 4: Orthogonal coefficients for contrast analyses.

\begin{tabular}{lccc}
\hline & & Group & \\
Contrast & ComG & TG & CG \\
\hline 1 & 1 & 1 & -2 \\
2 & 1 & -1 & 0 \\
\hline
\end{tabular}

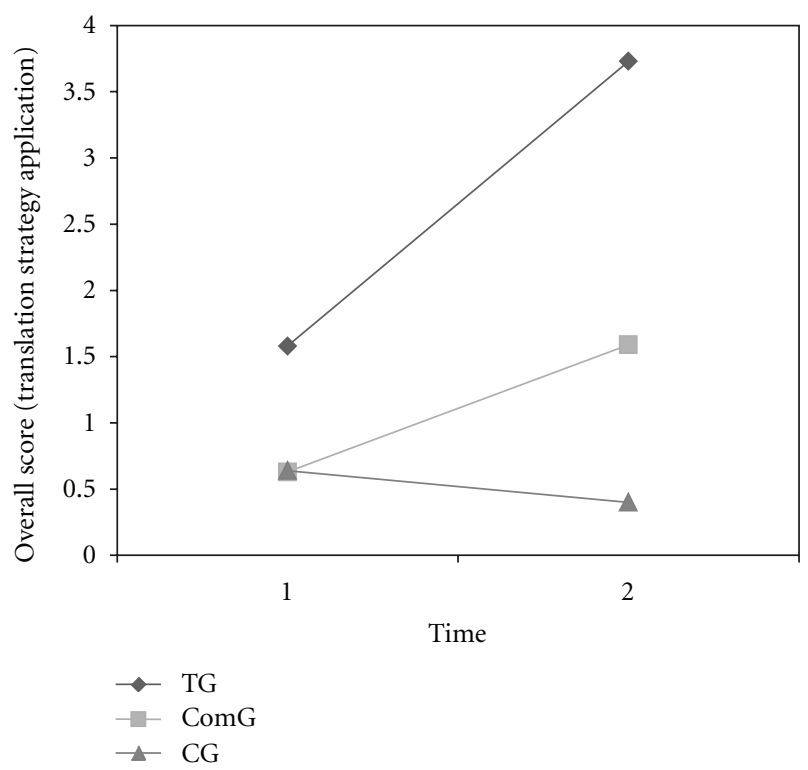

FIgURE 4: Results of the application of translation strategies.

group could not be performed. No additional effects were expected, but data should not reveal a decrease either.

In general, the results of the $t$-tests for stability measurement (cf. Table 6) show that there was no significant change for the variables between posttest and follow-up-test except for the achievement variables in the training group TG. As expected, no additional effect occurred after the intervention over a period of eight weeks. The students' self-regulatory competencies remained very stable in both groups, though they showed a slight but insignificant decrease. This implies that the intervention had only an effect during the actual training period.

The translation competency as well as the translation strategy application of the combined group was stable after the intervention and revealed an insignificant increase, whereas a significant decrease in both variables was observed for the translation-only group.

This result implies that participants of the TG had a lower level of translation competency and strategy application skills after a period of eight weeks.

\section{Discussion}

The purpose of the study was to investigate the effectiveness of two training programs in terms of self-regulated learning abilities and translation competencies of tenth grade students within their regular Latin class. Thereby, self-regulated learning was measured by students' general and Latin-related selfregulatory competencies. Students' academic achievement was measured by the quality of their translation and by the application of translation strategies. The intervention's effectiveness was examined by analyzing three different groups: a group that was taught both self-regulatory and translation strategies (ComG); a group that was only taught translation strategies (TG); and a group that did not receive any training, but was instructed by the regular teacher (CG).

The results of the pretest-posttest evaluation indicate that it is possible to enhance self-regulatory and translation competencies by an intervention program within regular Latin classes of tenth grade students in comparison to a control group without any special training. This was the finding we anticipated. The second hypothesis that postulated a predominance of the ComG in comparison to the TG could be unambiguously confirmed for no variable. For their selfregulatory competencies, students of the ComG showed 
TABLE 5: Results of a priori defined contrasts.

\begin{tabular}{|c|c|c|c|c|c|}
\hline & Contrast & Contrast value (SD) & $\mathrm{df}$ & $t$ & $r$ \\
\hline \multirow{2}{*}{ Overall self-regulated learning } & 1 & $0.26(0.13)$ & 106 & $2.02 *$ & 0.19 \\
\hline & 2 & $-0.15(0.08)$ & 106 & $-1.95^{\#}$ & 0.19 \\
\hline \multirow{2}{*}{ Translation competency } & 1 & $4.74(1.20)$ & 105 & $3.96^{* * *}$ & 0.36 \\
\hline & 2 & $1.40(0.70)$ & 105 & $2.01^{*}$ & 0.19 \\
\hline \multirow{2}{*}{ Translation strategy application } & 1 & $3.59(0.74)$ & 105 & $4.88^{* * *}$ & 0.43 \\
\hline & 2 & $1.19(0.43)$ & 105 & $2.78^{* *}$ & 0.26 \\
\hline
\end{tabular}

Note. ${ }^{\#} P<.10 ;{ }^{*} P<.05 ;{ }^{* *} P<.01 ;{ }^{* * *} P<.001 ; r$ : effect size.

TABLE 6: Results of the $t$-tests for stability measurement.

\begin{tabular}{|c|c|c|c|c|c|c|c|}
\hline Questionnaire & Group & $\begin{array}{l}\text { Posttest } \\
M \text { (SD) }\end{array}$ & $\begin{array}{l}\text { Stability } \\
M(\mathrm{SD})\end{array}$ & $\mathrm{df}$ & $t$ & $P$ & $d$ \\
\hline \multicolumn{8}{|l|}{ DV } \\
\hline \multirow{2}{*}{ Overall self-regulated learning (range 1-4) } & TG & $2.51(0.39)$ & $2.46(0.40)$ & 29 & 1.09 & 0.28 & 0.19 \\
\hline & ComG & $2.54(0.43)$ & $2.49(0.42)$ & 32 & 0.93 & 0.36 & 0.17 \\
\hline \multicolumn{8}{|l|}{ Translation test } \\
\hline \multirow{2}{*}{ Overall translation competence } & TG & $5.69(3.48)$ & $2.56(3.53)$ & 30 & 3.88 & 0.00 & 0.70 \\
\hline & ComG & $2.15(1.79)$ & $2.46(2.18)$ & 30 & -0.99 & 0.33 & 0.11 \\
\hline \multirow{2}{*}{ Translation strategy application } & TG & $3.73(2.75)$ & $1.54(2.07)$ & 30 & 4.36 & 0.00 & 0.79 \\
\hline & ComG & $1.42(1.56)$ & $1.52(1.64)$ & 30 & -0.34 & 0.74 & 0.18 \\
\hline
\end{tabular}

Note. TG: translation training only group $(N=32)$, ComG: combined group $(N=41)$.

- : increase; +: decrease; $d$ : effect size.

an increase, though significant only at the $10 \%$ level, compared to the students of the TG. Therefore, this result merely points in the direction that the additional teaching of selfregulated learning components predominates the teaching of translation strategies in terms of self-regulated learning skills. Accordingly, it can be regarded as a vague confirmation of findings of other studies $[12,39]$ which showed that the combination of self-regulatory and problem-solving strategies in mathematics leads to the best effects for the improvement of self-regulatory competencies.

The lacking predominance of the ComG in terms of selfregulatory behavior can be explained by the fact that the students might have been overwhelmed by self-regulatory components in Latin class. Students were, by their own account, used to the close guidance of their teachers, so that selfregulated learning and translating required a lot of effort and flexibility from them.

In terms of academic achievement, our findings indicated that it is possible to promote translation competencies as well as strategy application by training, since both ComG and TG showed a higher improvement than CG that even revealed a decline in both variables. Nevertheless, against our expectations, students of TG rather than students of ComG showed the highest increase in their translation competency as well as their strategy application, even though the ComG still reported an increase. The fact that the combined group did not profit more compared to the translation only group is neither in accordance with our assumptions nor with the results of other studies $[12,39]$. This result can be explained by different reasons: since the TG got 15 minutes more translation training per session than the ComG, the students of the TG got more exercise in terms of translation work, which surely is a limitation of the present study but is due to the fact that a deviation from the regular timetable was not possible. Future studies should therefore try to extend the ComG's session to 90-minutes training sessions in order to intensify the combination character of self-regulatory and domain-specific components. A further explanation for the lacking predominance of the ComG with regard to the translation competency and strategy application might be the mathematantic effect [49] which occurs in case that innovative treatments disrupt the learners' usual routine. In our case the students' accustomed approach to Latin texts might interfere with the development of self-regulatory abilities. Taking in consideration that a self-regulated strategic approach to Latin texts takes a long time, for the reason that Latin has a different structure from the German language and is highly inflected, this result can be regarded from a different perspective. It is found to be in line with research on strategic reading which was demonstrably revealed to be a long-term process [50]. In comparison to the ComG that had to engage themselves into two different kinds of unfamiliar strategies (self-regulatory and translation strategies) and to transfer them into daily routine, the TG only had to concentrate on a new translation approach.

To sum up, the results supported the assumption that a training program is effective to improve students' selfregulated learning behavior and academic achievement in comparison to a control group that continued the regular lessons. The fact that the combined training program did not 
reveal the expected effects in comparison to the translation group can be considered to be a matter of domain. Since the predominance of combined training programs was primarily found in mathematics [12, 39], it could be of interest to analyze this result also for the teaching of foreign languages.

Concerning the measurement of stability of intervention effects, we wanted to show that the effects were stable, that no additional effects can be found, and that there is no decrease for any variable. Taking in consideration that we had the dropout of the control group, our hypotheses could be approved with one exception: the students of the TG showed a decrease of both achievement variables. This result might be due to the Latin proficiency certificate that the students of the TG had to prepare in the period between posttest and stability measurement. The preparation for this important exam let them fall back on their usual strategy application and translation habits because they had to meet the strict requirements that the examination board as well as their teachers determined. That is why the change from the selfregulated approach practiced in the training to the regular instruction was more extreme for the TG than for the ComG. Nonetheless, it is remarkable that we could reveal stability of intervention effects after a longer period of time for the ComG in terms of self-regulatory competencies as well as of achievement variables. This result is an indication for the sustainability of the training of self-regulatory strategies in combination with domain-specific strategies.

The study's findings should not give ground for pessimism as it was the first empirical study that examined self-regulated learning and translation work in Latin class simultaneously. A change of habitual concepts and the establishment of a new strategy use need time. Against the background of this, the present study was a first step to raising the students' awareness for the importance of promoting crosscurricular competencies in that domain.

Nonetheless, there are limitations to this study that can be clearly specified. The prerequisites of a complete intervention design could not be met, because the recruitment of a group that would have been taught self-regulatory strategies only was not possible. Since teachers have to stick to the subject matter, it was not possible to find a teacher who was willing to neglect the curriculum's learning goals in favor of the impartment of cross-curricular competencies over a period of three weeks. Moreover, due to actualities of the school's situation, the participants could not be randomly assigned to the groups, which leads to an increase of external validity. This, however, was balanced by controlling for pretest differences.

A further limitation that has to be pointed out concerns the duration of the training program. Since our training program was designed as a first part of a larger intervention study, we confined ourselves to three weeks in order to be able to expand our procedure in the near future. Had the intervention been longer than three weeks, larger transfer effects of the training program may have been revealed, especially in terms of the internalization and automatization of strategy use [51]. Since other studies found that the effect sizes of intervention programs increased with the number of training sessions [52], we suggest longer interventions that would make an intensive and sustainable training possible, even though Hattie et al. [53] have shown that longer interventions have to be regarded against the background of a curvilinear trend between promotion and assessment of performance.

Another limitation refers to the measurement of the variables, because they are-except for the translation testbased on students' self-report data and may not be absolutely effective in accurately representing the constructs of interest. Self-report questionnaires are generally restricted in measuring self-regulated learning processes because conclusions regarding how far the students can actually regulate their learning are not possible [54]. However, they are directional for the assessment of a general aptitude to how one uses different self-regulatory processes [55]. For future research, we suggest considering additional measures, such as keeping learning diaries, interviewing, and making observation since these techniques could validate the results based on students' perceptions.

The present study implies practical consequences for prospective interventions providing that the design of the study is extended by a teacher training in which the instruction of self-regulated learning strategies is taught to and discussed with teachers. As findings of Waeytens et al. [56] showed teachers often are not aware of the concept of self-regulated learning and should therefore not only be provided by teaching material but also involved within the intervention of the study. This will have contributing effects on both the teachers' [57] as well as on the students' self-regulatory behavior [58] and will generally help to improve the teachers' understanding of their students' needs and their sense of imparting learning strategies [59].

The concept of our study definitely adds to research, as it established a good foundation for a transfer of self-regulatory strategies to translation tasks in Latin instruction and supported the implementation of self-regulated learning in regular class settings. Hence, an integration of self-regulatory strategies into regular Latin class should be initiated to positively influence both the development of self-regulatory learning behavior and translation competency so that a strategic approach to Latin texts can also be promoted in an earlier state of the students' school career.

\section{References}

[1] B. J. Zimmerman, "Theories of self-regulated learning and academic achievement: an overview and analysis," in SelfRegulated Learning and Academic Achievement: Theoretical Perspectives, B. J. Zimmerman and D. H. Schunk, Eds., pp. 137, Erlbaum, Mahwah, NJ, USA, 2nd edition, 2001.

[2] F. Perels, M. Merget-Kullmann, M. Wende, B. Schmitz, and C. Buchbinder, "Improving self-regulated learning of preschool children: evaluation of training for kindergarten teachers," British Journal of Educational Psychology, vol. 79, no. 2, pp. 311-327, 2009.

[3] W. Schneider and K. Lockl, "The development of metacognitive knowledge in children and adolescents," in Applied Metacognition, T. Perfect and B. L. Schwartz, Eds., pp. 224257, Cambridge University Press, Cambridge, UK, 2002. 
[4] T. Doepner, "Keine Förderung ohne Diagnose. Beispiele für kriterienorientierte Beobachtung in der Spracherwerbsphase," Altsprachlicher Unterricht, vol. 51, no. 1, pp. 14-22, 2008.

[5] S. Sharoff, "Translation as problem solving: uses of comparable corpora," in Proceedings of the Language Resources for Translation Research and Practice at LREC2006, Genoa, Italy, May 2006.

[6] L. Haag and E. Stern, "In search of the benefits of learning Latin," Journal of Educational Psychology, vol. 95, no. 1, pp. 174-178, 2003.

[7] R. Masciantonio, "Tangible benefits of the study of Latin: a review of research," Foreign Language Annals, vol. 10, no. 4, pp. 375-382, 1977.

[8] S. Thies, "Lesekompetenz. Lateinunterricht und PISA," Altsprachlicher Unterricht, vol. 46, pp. 2-3, 2003.

[9] R. A. LaFleur, "Latin students score high on SAT and achievement tests," Classical Journal, vol. 76, no. 3, p. 254, 1981.

[10] M. Keip and T. Doepner, Interaktive Fachdidaktik Latein, Vandenhoeck \& Ruprecht, Göttingen, Germany, 2010.

[11] P. R. Pintrich, "The role of goal orientation in self-regulated learning," in Handbook of Self-Regulation, M. Boekaerts, P. R. Pintrich, and M. Zeidner, Eds., pp. 451-502, Academic Press, San Diego, Calif, USA, 2000.

[12] F. Perels, T. Gürtler, and B. Schmitz, "Training of self-regulatory and problem-solving competence," Learning and Instruction, vol. 15, no. 2, pp. 123-139, 2005.

[13] E. Nida and C. Taber, The Theory and Practice of Translation, E. J. Brill, Leiden, The Netherlands, 1969.

[14] H. J. Glücklich, Lateinunterricht. Didaktik und Methodik, Vandenhoeck \& Ruprecht, Göttingen, Germany, 2008.

[15] F. Perels, S. Bruder, R. Bruder, and B. Schmitz, "Erfolgreicher Mathematik lernen,” Praxis Schule 5-10, vol. 5, pp. 10-14, 2004.

[16] B. J. Zimmerman, "Attaing self-regulation: a social cognitive perspective," in Handbook of Self-Regulation, M. Boekaerts, P. R. Pintrich, and M. Zeidner, Eds., pp. 13-39, Elsevier, Academic Press, Burlington, Mass, USA, 2000.

[17] C. S. Dweck, Self-Theories: Their Role in Motivation, Personality, and Development, Psychology Press, Philadelphia, Pa, USA, 1999.

[18] A. Bandura, Self-Efficacy: The Exercise of Control, Freeman, New York, NY, USA, 1997.

[19] A. Wigfield and J. S. Eccles, "The development of achievement task values: a theoretical analysis," Developmental Review, vol. 12, no. 3, pp. 265-310, 1992.

[20] T. W. Malone and M. R. Lepper, "Making learning fun: a taxonomy of intrinsic motivations for learning," in Aptitude, Learning and Instruction Volume 3: Conative and Affective Process Analyses, R. E. Snow and M. J. Farr, Eds., Erlbaum, Hillsdale, NJ, USA, 1987.

[21] R. M. Ryan and E. L. Deci, "Self-determination theory and the facilitation of intrinsic motivation, social development, and well-being," American Psychologist, vol. 55, no. 1, pp. 68-78, 2000.

[22] L. Nota, S. Soresi, and B. J. Zimmerman, "Self-regulation and academic achievement and resilience: a longitudinal study," International Journal of Educational Research, vol. 41, no. 3, pp. 198-215, 2004.

[23] B. J. C. Claessens, W. van Eerde, C. G. Rutte, and R. A. Roe, "A review of the time management literature," Personnel Review, vol. 36, no. 2, pp. 255-276, 2007.

[24] L. Corno, "The metacognitive control components of selfregulated learning," Contemporary Educational Psychology, vol. 11, no. 4, pp. 333-346, 1986.
[25] C. E. Weinstein and R. E. Mayer, "The teaching of learning strategies," in Handbook of Research on Teaching, M. C. Wittrock, Ed., pp. 315-327, Macmillan, New York, NY, USA, 1986.

[26] L. Corno, "Introduction to the special issue work habits and work styles: volition in education," Teachers College Record, vol. 106, no. 9, pp. 1669-1694, 2004.

[27] M. Boekaerts and M. Niemivirta, "Self-regulation in learning: finding a balance between learning- and ego-protective goals," in Handbook of Self-Regulation, M. Boekaerts, P. R. Pintrich, and M. Zeidner, Eds., pp. 417-450, Academic Press, San Diego, Calif, USA, 2000.

[28] C. A. Wolters, "Understanding procrastination from a selfregulated learning perspective," Journal of Educational Psychology, vol. 95, no. 1, pp. 179-187, 2003.

[29] B. Weiner, An Attributional Theory of Motivation and Emotion, Springer, New York, NY, USA, 1986.

[30] R. Brooks and S. Goldstein, The Power of Resilience: Achieving Balance, Confidence, and Personal Strength in Your Life, McGraw-Hill, New York, NY, USA, 2004.

[31] P. R. Pintrich, D. A. R. Smith, T. Garcia, and W. McKeachie, A Manual for the Use of the Motivated Strategies for Learning Questionnaire (MSLQ), University of Michigan, Ann Arbor, Mich, USA, 1991.

[32] P. H. Winne and N. E. Perry, "Measuring self-regulated learning," in Handbook of Self-Regulation, M. Boekaerts, P. Pintrich, and M. Zeidner, Eds., pp. 531-566, Academic Press, San Diego, Calif, USA, 2000.

[33] C. E. Weinstein, A. Schulte, and D. R. Palmer, The Learning and Study Strategies Inventory, H \& H Publishing, Clearwater, Fla, USA, 1987.

[34] K. P. Wild and U. Schiefele, "Learning strategies of university students: factor structure and reliability of a new questionnaire," Journal of Differential and Diagnostic Psychology, vol. 15, no. 4, pp. 185-200, 1994.

[35] M. Boekaerts and L. Corno, "Self-regulation in the classroom: a perspective on assessment and intervention," Applied Psychology, vol. 54, no. 2, pp. 199-231, 2005.

[36] C. Dignath, G. Büettner, and H. P. Langfeldt, "How can primary school students learn self-regulated learning strategies most effectively? A meta-analysis on self-regulation training programmes," Educational Research Review, vol. 3, no. 2, pp. 101-129, 2008.

[37] L. S. Fuchs, D. Fuchs, K. Prentice et al., "Enhancing thirdgrade students' mathematical problem solving with self-regulated learning strategies," Journal of Educational Psychology, vol. 95, no. 2, pp. 306-315, 2003.

[38] F. Perels, C. Dignath, and B. Schmitz, "Is it possible to improve mathematical achievement by means of self-regulation strategies? Evaluation of an intervention in regular math classes," European Journal of Psychology of Education, vol. 24, no. 1, pp. 17-31, 2009.

[39] B. Kramarski and M. Gutman, "How can self-regulated learning be supported in mathematical E-learning environments?" Journal of Computer Assisted Learning, vol. 22, no. 1, pp. 24-33, 2006.

[40] T. J. Cleary and P. P. Chen, "Self-regulation, motivation, and math achievement in middle school: variations across grade level and math context," Journal of School Psychology, vol. 47, no. 5, pp. 291-314, 2009.

[41] D. Leutner, A. Barthel, and B. Schreiber, "Studierende können lernen, sich selbst zum Lernen zu motivieren: Ein Trainingsexperiment," Zeitschrift für Pädagogische Psychologie, vol. 15, no. 3-4, pp. 155-167, 2001. 
[42] E. Souvignier and J. Moklesgerami, "Using self-regulation as a framework for implementing strategy instruction to foster reading comprehension," Learning and Instruction, vol. 16, no. 1, pp. 57-71, 2006.

[43] S. Graham and K. R. Harris, "The role of self-regulation and transcription skills in writing and writing development," Educational Psychologist, vol. 35, no. 1, pp. 3-12, 2000.

[44] P. D. Shen, T. H. Lee, and C. W. Tsai, "Applying webenabled problem-based learning and self-regulated learning to enhance computing skills of Taiwan's vocational students: a quasi-experimental study of a short-term module," The Electronic Journal of E-Learning, vol. 5, no. 6, pp. 147-156, 2007.

[45] P. Chularut and T. K. DeBacker, "The influence of concept mapping on achievement, self-regulation, and self-efficacy in students of English as a second language," Contemporary Educational Psychology, vol. 29, no. 3, pp. 248-263, 2004.

[46] W. T. Tseng, Z. Dörnyei, and N. Schmitt, "A new approach to assessing strategic learning: the case of self-regulation in vocabulary acquisition," Applied Linguistics, vol. 27, no. 1, pp. 78102, 2006.

[47] N. D. Yang, “The relationship between EFL learners' beliefs and learning strategy use," System, vol. 27, no. 4, pp. 515-535, 1999.

[48] R. M. Ryan and J. P. Connell, "Perceived locus of causality and internalization: examining reasons for acting in two domains," Journal of Personality and Social Psychology, vol. 57, no. 5, pp. 749-761, 1989.

[49] R. E. Clark, "When teaching kills learning: studies of mathematantics," in Learning and Instruction: European Research in an International Context, H. Mandl, E. De Corte, N. S. Bennet, and H. F. Friedrich, Eds., pp. 1-22, Pergamon Press, Oxford, UK, 1990 .

[50] J. T. Guthrie, P. van Meter, G. R. Hancock, S. Alao, E. Anderson, and A. McCann, "Does concept-oriented reading instruction increase strategy use and conceptual learning from text?" Journal of Educational Psychology, vol. 90, no. 2, pp. 261278, 1998.

[51] M. Pressley, B. L. Snyder, and T. Cariglia-Bull, "How can good strategy use be taught to children? Evaluation of six alternative approaches," in Transfer of Learning, S. Cormier and J. D. Hagman, Eds., pp. 81-120, Academic Press, San Diego, Calif, USA, 1987.

[52] C. Dignath and G. Büttner, "Components of fostering selfregulated learning among students. A meta-analysis on intervention studies at primary and secondary school level," Metacognition and Learning, vol. 3, no. 3, pp. 231-264, 2008.

[53] J. Hattie, J. Biggs, and N. Purdie, "Effects of learning skills interventions on student learning: a meta-analysis," Review of Educational Research, vol. 66, no. 2, pp. 99-136, 1996.

[54] N. Spörer and J. C. Brunstein, "Erfassung selbstregulierten Lernens mit Selbstberichtsverfahren: Ein Überblick zum Stand der Forschung," Zeitschrift für Pädagogische Psychologie, vol. 20, no. 3, pp. 147-160, 2006.

[55] P. R. Pintrich, "A motivational science perspective on the role of student motivation in learning and teaching contexts," Journal of Educational Psychology, vol. 95, no. 4, pp. 667-686, 2003.

[56] K. Waeytens, W. Lens, and R. Vandenberghe, "Learning to learn: teachers' conceptions of their supporting role," Learning and Instruction, vol. 12, no. 3, pp. 305-322, 2002.

[57] M. Cardelle-Elawar, L. Irwin, and M. L. Sanz de Acedo Lizarraga, "A cross-cultural analysis of motivational factors that influence teacher identity," Electronic Journal of Research in Educational Psychology, vol. 5, pp. 565-592, 2007.
[58] L. Kremer-Hayon and H. H. Tillema, "Self-regulated learning in the context of teacher education," Teaching and Teacher Education, vol. 15, no. 5, pp. 507-522, 1999.

[59] S. G. Paris and P. Winograd, "The role of self-regulated learning in contextual teaching: principles and practices for teacher preparation," 2001, http://www.ciera.org/library/archive/ 2001-04/0104parwin.htm. 

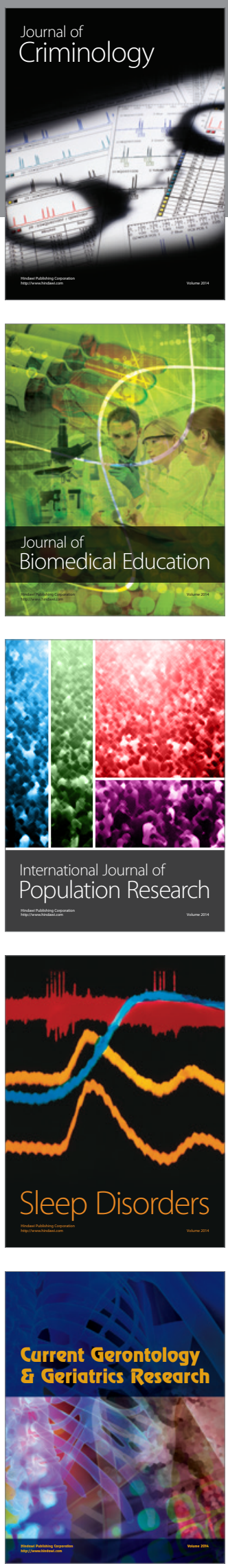
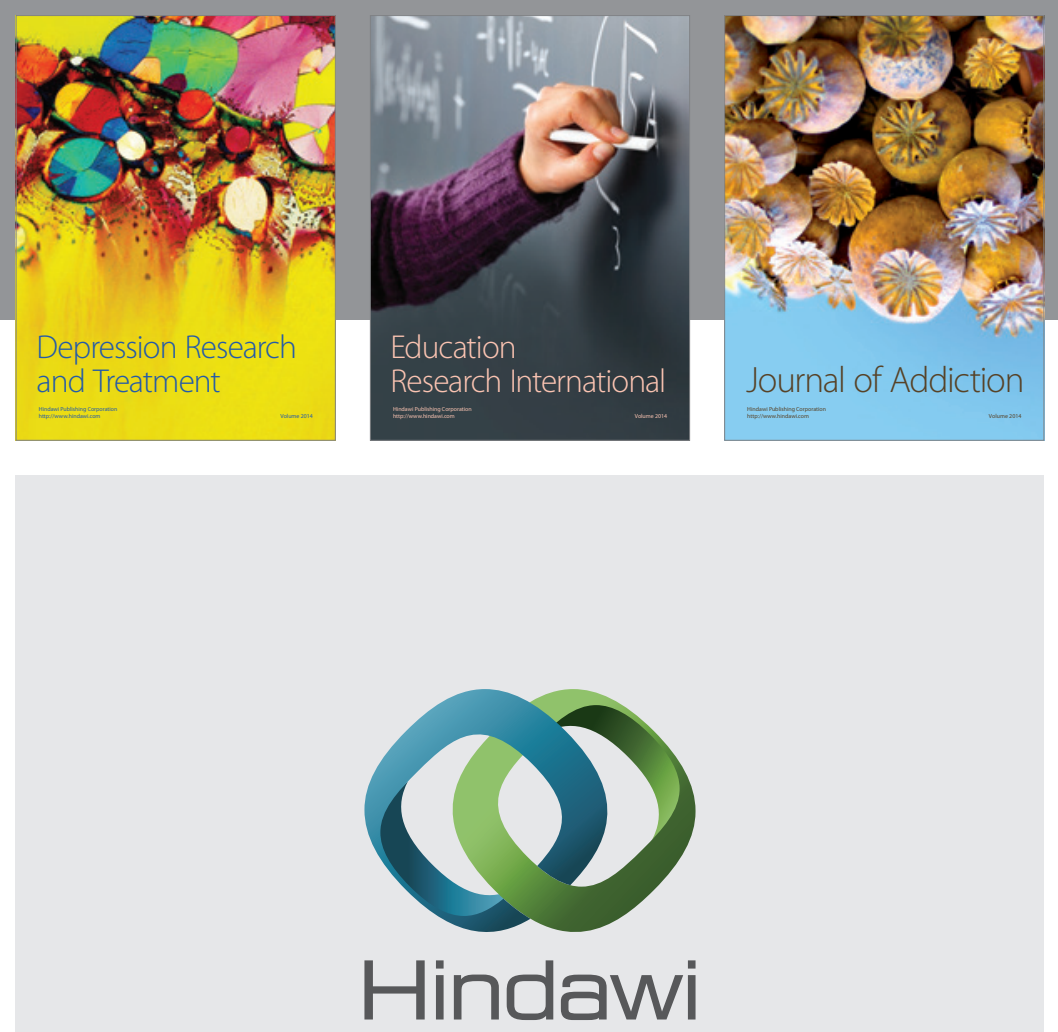

Submit your manuscripts at

http://www.hindawi.com

Child Development Research
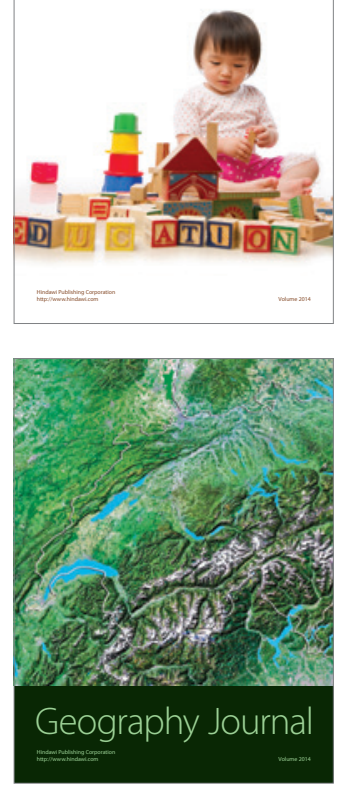

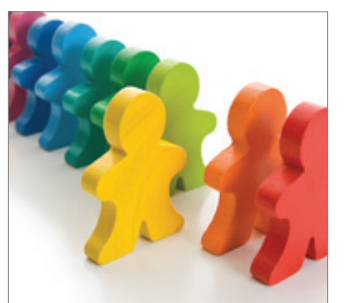

Autism

Research and Treatment
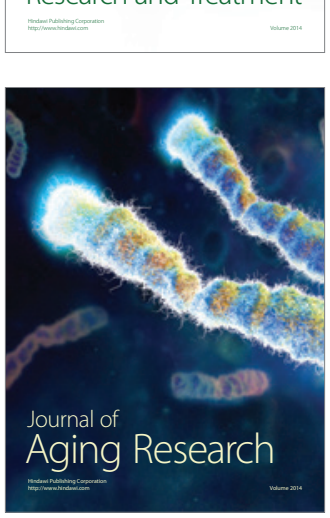
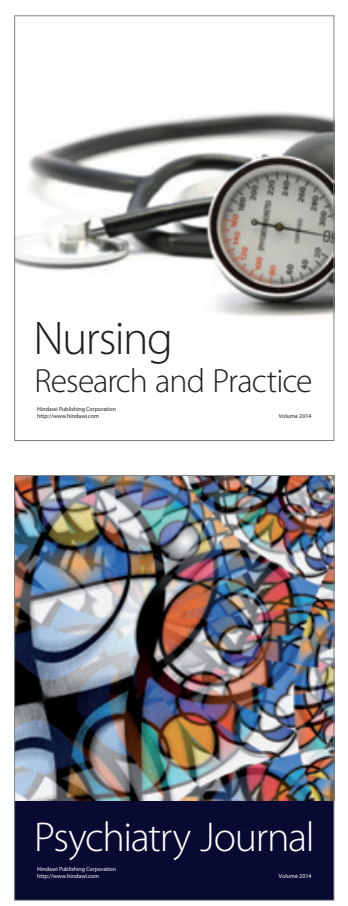
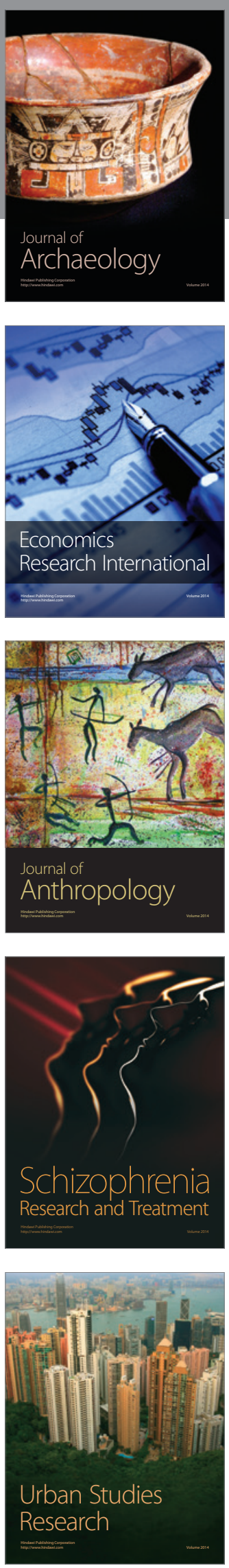